\title{
Experimental evaluation of piston motion modification to improve the thermodynamic power output of a low temperature gamma Stirling engine
}

\author{
Michael Nicol-Seto ${ }^{1}$, and David Nobes ${ }^{1 *}$ \\ ${ }^{1}$ University of Alberta, Mechanical Engineering Department, 9211116 Street NW, Canada
}

\begin{abstract}
Stirling engines are a variety of heat engines which are capable of using heat from various sources including low temperature renewables. This work examines performance of a lab scale low temperature gamma type Stirling engine with a drive train modified with oval elliptical gears. The gears were added to dwell the engine piston motion to attempt to improve the thermodynamic performance of the engine by better replicating the ideal Stirling cycle. A variety of dwelling piston configurations were tested on both the displacer and power piston. It was observed that that the piston dwelling had the anticipated effect of changing the engine indicator diagrams to more closely resemble the ideal cycle, however there were no substantial improvements to maximum engine power. It was observed that dwelling the displacer piston caused substantial reductions to engine running speeds and resulted in maximum power being reduced. In the case of power piston dwelling the indicator diagram was enlarged and there were slight increases to maximum power production. Overall the added complexity of dwelled piston motion systems is not likely an advantageous method of increasing the power output of low temperature difference Stirling engines.
\end{abstract}

\section{Introduction}

Stirling engines are a variety of thermodynamic engines that run off of external thermal sources and sinks. Their ability to use a wide variety of heat sources has spurred interest in developing Stirling engines for renewable energy recovery from sources such as solar [1] and biomass [2], as well as potentially very low temperature difference heat sources such as waste heat [3] or low grade geothermal sources [4]. The useful mechanical energy available for thermodynamic conversion at low temperature ratios (below $100{ }^{\circ} \mathrm{C}$ ) is inherently low, with a Carnot limit of $\sim 25 \%$ efficiency at a source temperature of $100{ }^{\circ} \mathrm{C}$ and a sink temperature of $5{ }^{\circ} \mathrm{C}$. For practical engines, efficiencies are much lower still [5]. As such it is desirable to maximize the thermodynamic yield of these low temperature engines by any available means.

A suggested method for improving power is to better replicate the ideal thermodynamic cycle by modifying the engine drive mechanism to dwell the engine pistons [6]. This work details the construction and testing of a lab scale low temperature difference gamma Stirling

\footnotetext{
*Corresponding author: dnobes@ualberta.ca
} 
engine whose drive mechanism was modified with non-circular oval elliptical gearing that better replicates the ideal Stirling thermodynamic cycle. Performance results of the engine are provided with recommendations as to the utility of such modifications on low temperature engines.

\section{The Stirling Cycle and Kinematic Engines}

\subsection{Thermodynamic Cycle of a Practical Engine}

The Stirling cycle is a heat engine where only heat flows through the engine while a captive mass of compressible working fluid contained in the engine undertakes the thermodynamic cycle of the engine. The classic academic description of the Stirling cycle describes the thermodynamic processes as discrete, sequential steps of the closed loop cycle. This ideal cycle is described by the following processes with reference to Figure 1 [7]:

1. Isochoric heating

2. Isothermal expansion

3. Isochoric cooling

4. Isothermal expansion

The indicated work done by the engine per cycle $W$ is the difference between the absolute expansion work, $W_{e}$, minus the absolute compression work, $W_{c}$, as described by the following [8]:

$$
W=W_{e}-W_{c}=\int_{V_{\max }}^{V_{\min }} P_{e}(V) d V-\int_{V_{\max }}^{V_{\min }} P_{c}(V) d V
$$

where

$$
\begin{aligned}
& V_{\min }=\text { Minimum engine volume } \\
& V_{\text {max }}=\text { Maximum engine volume } \\
& P_{e}=\text { Expansion pressure } \\
& P_{c}=\text { compression pressure }
\end{aligned}
$$

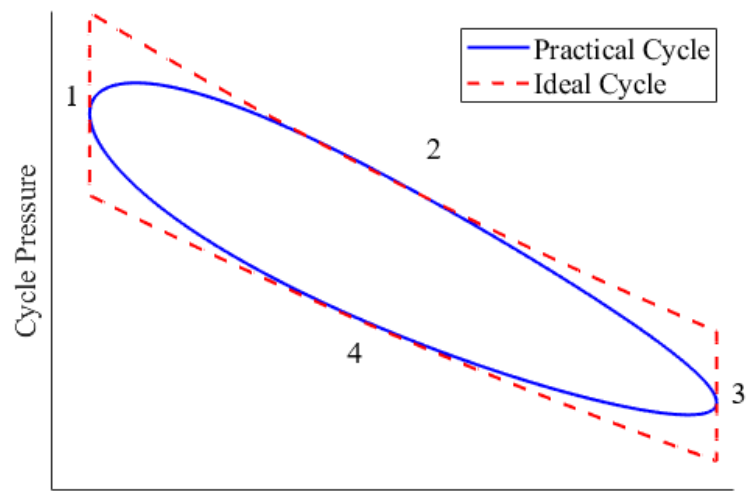

Engine Volume

Figure 1. Representative pressure volume diagram of the ideal and practical Stirling cycle. 
The loop formed by the cycle expressed by the engine pressure and volume is commonly referred to as the engine indicator diagram as shown in Figure 1. In practical engines, the mechanisms by which the cycle is carried out results in overlaps in the steps of the thermodynamic processes, which has the resulting effect of the rounding and reduction of the indicated work area of the cycle when compared to an ideal cycle carried out for the same conditions. Expanding the practical indicator diagram can potentially increase the available work per cycle of the engine, and if done without other penalty, may thus increase the power output.

\subsection{The Kinematic Gamma Stirling Engine}

Numerous variants of the Stirling cycle machine have been developed over time and are commonly classified based on the way each machine moves the engine working fluid to carry out the thermodynamic cycle [7]. This work focuses on kinematic gamma type Stirling engines [4], where kinematic indicates that the piston motions are mechanically linked and controlled via the drive mechanism. The defining characteristic of a gamma Stirling engine is that it has two piston cylinder sets as embodied in Figure 2. The isochoric heating and cooling phases are carried out by the movement of a displacer piston, which shuttles the working fluid from the expansion space of the engine to the compression space. In most large engines the gas path routs the working fluid through a set of heat exchangers and a regenerator which are the primary means of transferring heat into and out of the working space of the engine [7]. The compression and expansion phases of the cycle are accomplished via a power piston, which is driven by the differential pressure of the engine working fluid and the pressure outside of the working space, referred to as the buffer pressure [8].

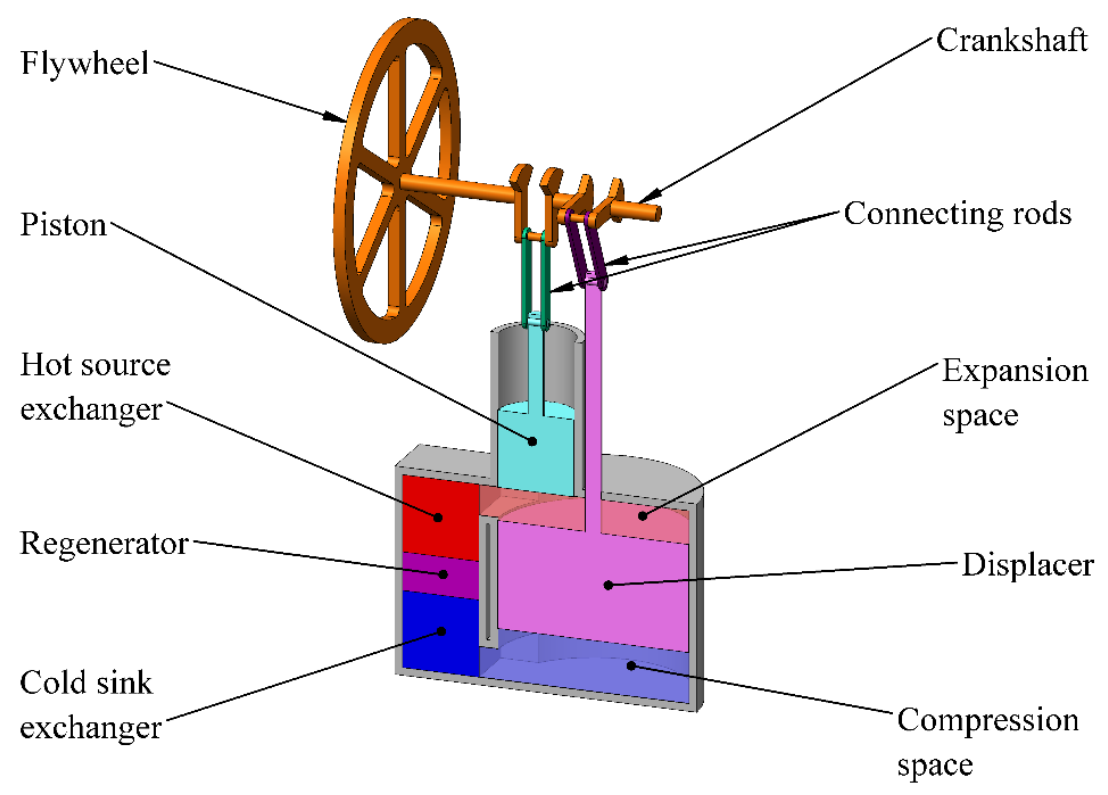

Figure 2. Generalized embodiment of an offset gamma Stirling engine depicting the major components.

For most kinematic engines the pistons are linked to a common rotating output shaft via a slider-crank mechanism that converts between linear and rotational motion in an 
approximately sinusoidal relationship. For gamma engines the work done by the power piston drives the output shaft, while the displacer piston is driven by the same shaft, sustaining the cycle. The phasing difference between the motions of the two pistons is what causes the sequential thermodynamic processes to form the Stirling cycle. For gamma engines, a phase difference of $90^{\circ}$ is most optimal [9].

The overlapping motion of the displacer and power pistons result in the thermodynamic steps of the cycle overlapping as well. The thermodynamic overlap results in a practical cycle indicator diagram that is smaller and rounder than the ideal cycle as shown in Figure 1, with the associated loss of work output per cycle. If the overlap in piston motion can be reduced and the associated thermodynamic processes made more discontinuous, there is the opportunity to improve the practical engine indicator cycle to one that more closely replicates the ideal case with greater work per cycle.

\section{Cycle Modification Using Non-Circular Gears}

Various mechanisms have been proposed to be integrated into the engine drive mechanisms to achieve more discontinuous cycles with the aim of expanding the indicated work. Such methods have included using a cam follower drive [10], multi bar linkages [11], and elliptical gear trains [12] to modify piston motion by changing the rotational speeds of the piston crank arms relative to the constant speed engine output shaft.

The decision to modify piston motion with non-circular gears was made due to the ease of retrofitting an existing engine with the system, as well as the flexibility of interchanging multiple gear sets to test various motion modification profiles. A generalized embodiment of a kinematic gamma Stirling engine modified with non-circular gears is depicted in Figure 3.

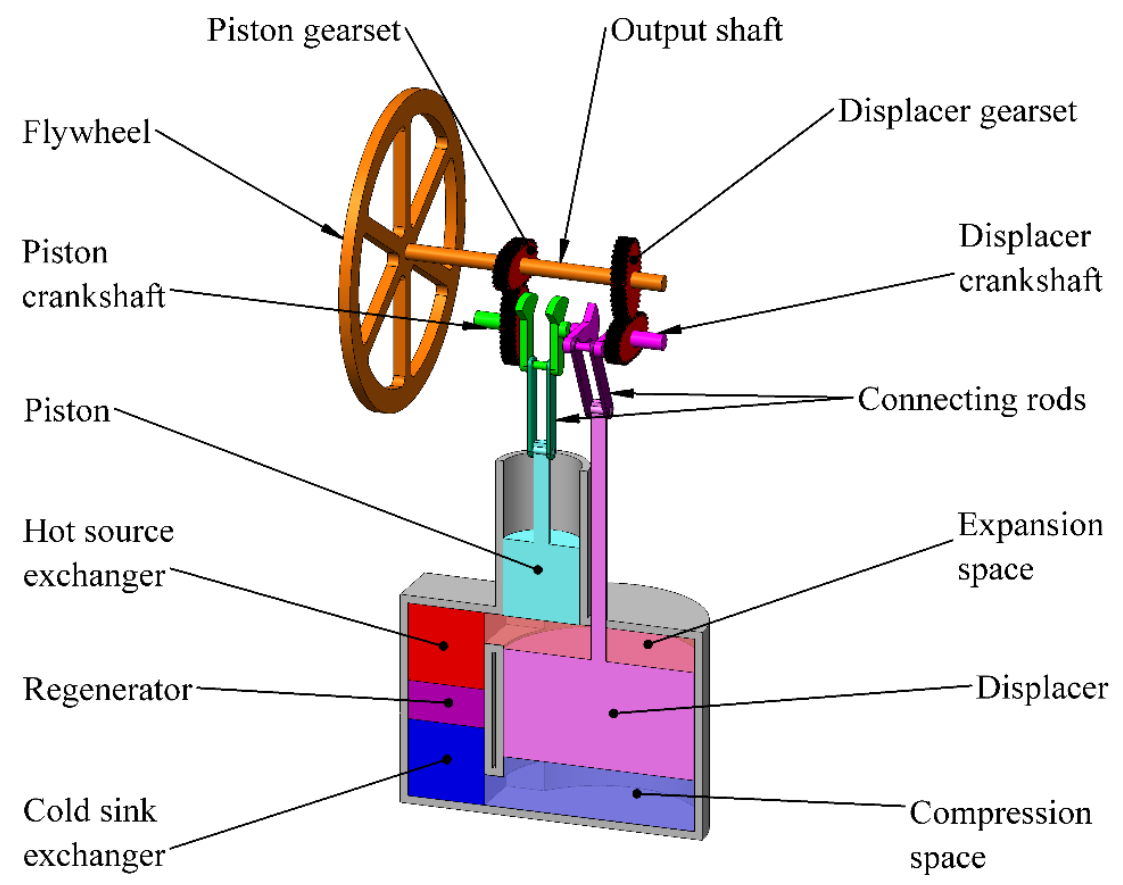

Figure 3. Embodiment of an offset gamma Stirling engine with a modified drive train with noncircular gears. 
The non-circular gear profile used were bi-lobed elliptical profiles, also known as oval elliptical profiles [13]. For identical oval non-circular gear pairs the relationship between the angle of the input shaft, $\varnothing_{1}$, and the angle of the output shaft, $\varnothing_{2}$, as governed by the transmission function is:

$$
\tan \emptyset_{2}=\frac{1-e}{1+e} \tan \emptyset_{1}
$$

where

$$
\begin{aligned}
& \emptyset_{2}=\text { Angular position of driven gear } \\
& \emptyset_{1}=\text { Angular position of driving gear } \\
& e=\text { Eccentricity of oval elliptical gear }
\end{aligned}
$$

The derivative function, or speed ratio, which describes the relative angular velocity of the driven gear with respect to the driving dear is defined by:

$$
k_{21}=\frac{1-e^{2}}{1+e^{2}-2 e\left(\cos 2 \emptyset_{1}\right)}
$$

where

$$
\begin{aligned}
& k_{21}=\text { derivative function of gear } 2 \text { in relation to gear } 1 \\
& \emptyset_{1}=\text { Angular position of driving gear } \\
& e=\text { Eccentricity of oval elliptical gear }
\end{aligned}
$$

The derivative function and transmission functions for oval elliptical gears cycle twice per revolution which matches the cycle modification requirement for dwelling the engine pistons twice per cycle. Two oval elliptical gear profiles were chosen for the investigation, $e=1 / 5$ and $e=1 / 3$ based on the maximum derivative function value of each set being $k_{21}=1.5$ and $k_{21}=2.0$.

By phasing the lobes of the oval gears with the crank arms, the dwell time of the pistons at top and bottom dead centre positions is prolonged. The displacement profiles of a set of engine pistons based on an engine configured as in Figure 3 is shown in Figure 4. The displacement profiles are derived from the $\sin \left(\emptyset_{2}\right)$ value of the output of the transmission function described in equation (3) when applying various gear eccentricities to the angular position of the output shaft $\emptyset_{1}$. This approximates the displacement of a piston coupled to a crank-slider mechanism with a very long connecting rod. 


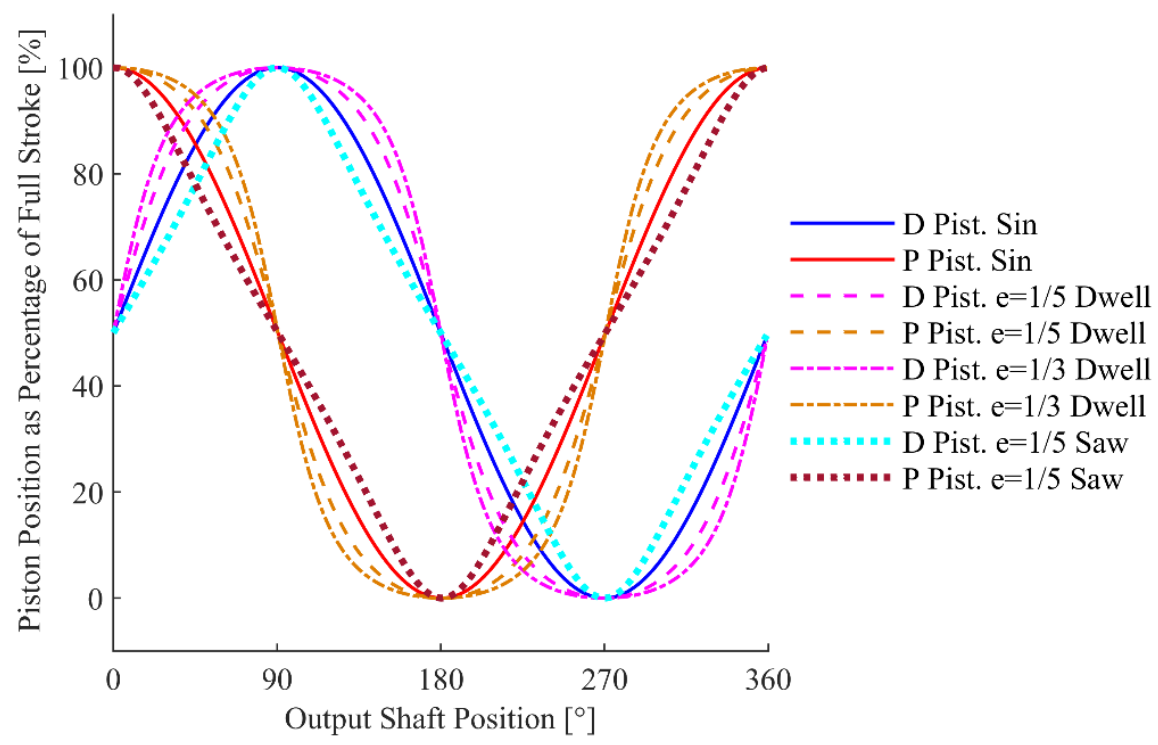

Figure 4. Normalized displacement of engine pistons for various combinations of non-circular gearing and crank shaft phasing.

Examining Figure 4 it can be seen that when phased appropriately, the oval elliptical non-circular gears are capable of substantially increasing the duration of dwell of the engine pistons at top and bottom dead center. The reduction in overlap of the displacer piston and power piston motion should result in more discrete thermodynamic processes in the practical Stirling cycle in line with the goals of the investigation. When phased $90^{\circ}$ relative to the crank arm the gears are also capable of reducing dwell, with the $e=1 / 5$ gear showing a distinctly triangular displacement waveform.

\section{Experimental Setup}

\subsection{EP1 - M Test Engine}

To test the effects of piston motion modification using non-circular gearing a lab scale gamma Stirling engine was modified with a new drivetrain. The original engine, named the EP1, was designed and built in 2018 [14] [15], for operation at temperature differentials between $0{ }^{\circ} \mathrm{C}$ and $100{ }^{\circ} \mathrm{C}$. The engine is a kinematic gamma engine design with an offset power piston. Numerous modifications have been made to the engine to improve its performance since its construction to bring it up to the current EP1-M configuration which is shown in partial section view in Figure 5. This work details the engine as configured for the trial of the modified piston motion profiles.

The body of the engine is manufactured from two piping flanges welded to form the working space of the engine. Two caps enclose the volume, with the upper cap mounting the power piston, the displacer piston rod, and supporting the engine drive mechanism frame. The heat exchangers of are formed from two identical banks of finned tube mounted in the annular gap between the displacer piston cylinder and the outer engine body. A regenerator is present and takes the form of series of thin rectangular channels which are 3D printed in ABS plastic. The displacer piston is constructed from rigid closed cell polystyrene foam to minimize reciprocating mass. A novel element of the engine is the use of a reinforced 
elastomeric pleated bellow for the engine power piston which was included to reduce friction present in more conventional sliding seal piston cylinder sets. The basic engine specifications are presented in Table 1.

Table 1. EP1-M engine specifications.

\begin{tabular}{lcc}
\hline Engine Property & Value & Units \\
\hline Working Fluid & Air & - \\
Engine Charge / Buffer Pressure & Atmospheric & $\mathrm{kPa}$ \\
Displacer Swept Volume & 5.69 & $\mathrm{~L}$ \\
Power Piston Swept Volume & 1.78 & $\mathrm{~L}$ \\
Dead Volume & 3.42 & $\mathrm{~L}$ \\
Dead Volume Ratio & 0.60 & - \\
Compression Ratio & 1.2 & - \\
Piston Phasing & 90 & $\circ$ \\
\hline
\end{tabular}

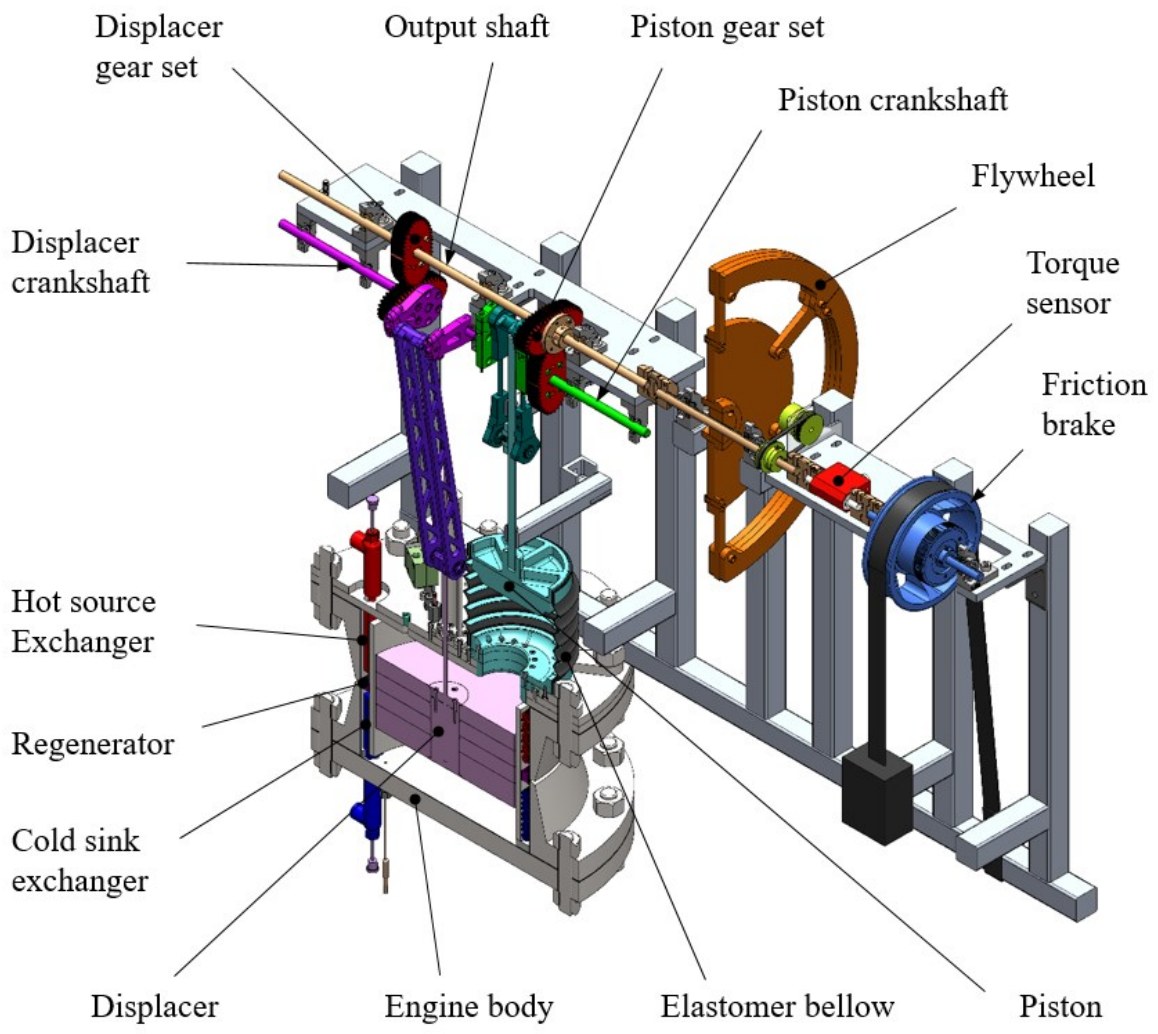

Figure 5. Partial section view of the EP1 - M low temperature difference gamma Stirling engine. 
To accommodate the use of non-circular gears the original slider-crank drive mechanism of the EP1 was removed and replaced with a new mechanism as shown in Figure 5. The new mechanism features independent slider-crank mechanisms for each piston that is driven by a set of interchangeable gears. The engine flywheel was also enlarged to minimize output shaft velocity fluctuations to best achieve the desired velocity fluctuations in the piston cranks. Power take off of the engine is provided by a friction brake system. The drum of the brake is draped with a strap that can be progressively weighted to change the load applied to the engine.

\subsection{Engine Instrumentation and Data Collection}

An instrumented test rig is coupled to the engine which supplies the thermal energy to run the engine while also allowing monitoring and recording of the engine performance while in operation [14]. Figure 6 depicts the instrumentation and support layout of the test rig used on the EP1-M. The thermal source of the engine is hot water supplied from a hot water bath while the thermal sink of the engine is chilled water supplied from a cold water bath. Both thermal loops are controlled by a multi-head programmable peristaltic pump that circulates the thermal fluid directly in the engine heat exchangers. For all trails of the engine the operating parameters of the thermal loop were held constant at the conditions shown in Table 2.

Engine data was recorded from a suite of instruments mounted to the EP1-M to measure its performance in the layout shown in Figure 6. Direct measurements of the following parameters could be monitored live and were recorded during trials:

- Output shaft position

- Gauge pressure of the expansion space

- Torque output of the engine output shaft

- Working fluid temperatures at the heat exchanger exits

- Thermal source and sink loop temperatures at the exchanger ports

- Time

For each trial set the engine was run from unloaded free running state up to stall point and back down to unloaded free running by adding and removing fixed increments of mass to the friction brake strap. The engine was given time to reach steady state operation at the load prior to collecting data. For each data set the atmospheric buffer pressure conditions were measured and all instruments were recorded for 20s. Two back-to-back runs from unloaded to stall, back down to unloaded were conducted for each trial gear configuration, with data recorded each loading point on the runs. Transient engine running data between loading applications was not recorded.

Table 2. Test Conditions.

\begin{tabular}{lcc}
\hline Property & Value & Units \\
\hline Thermal Source Fluid & Water & - \\
Source Temperature & $92.6 \pm 0.4$ & ${ }^{\circ} \mathrm{C}$ \\
Source Supply Rate & $1.94 \pm 0.01$ & $\mathrm{~kg} / \mathrm{min}$ \\
Thermal Sink Fluid & Water & - \\
Sink Temperature & $4.7 \pm 0.4$ & ${ }^{\circ} \mathrm{C}$ \\
Sink Supply Rate & $1.75 \pm 0.01$ & $\mathrm{~kg} / \mathrm{min}$ \\
Brake Loading Increment & 71 & $\mathrm{~g}$ \\
\hline
\end{tabular}




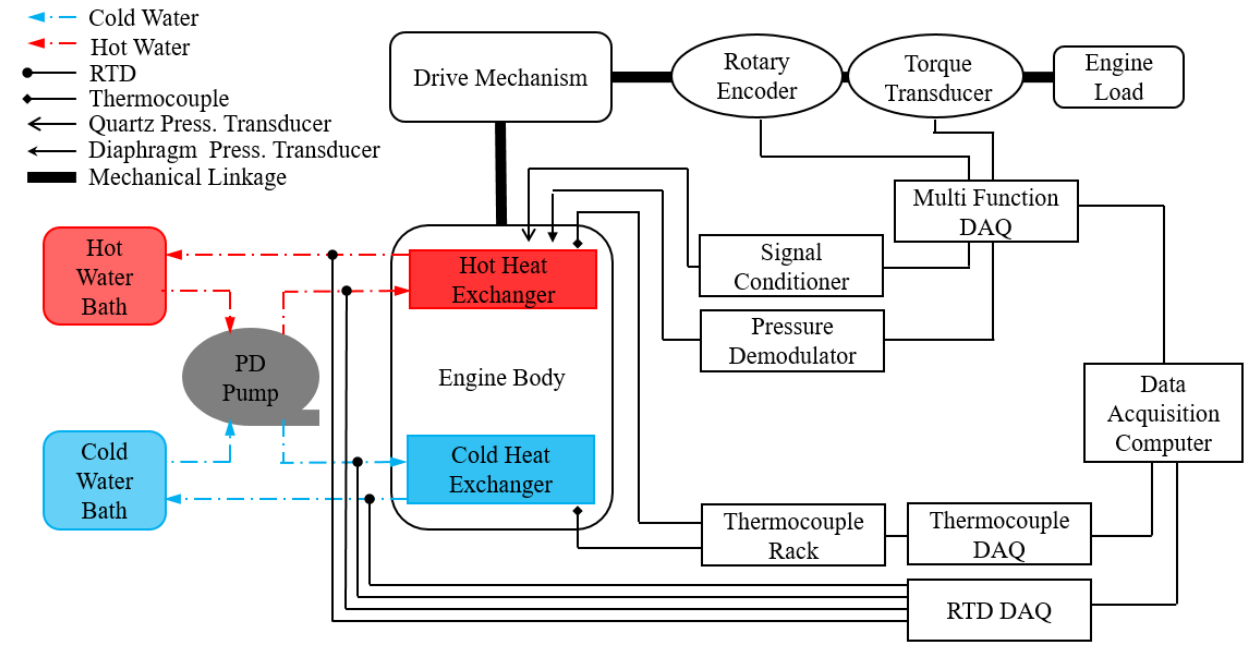

Figure 6. Engine instrumentation and support test rig diagram.

\subsection{Trial Configurations}

To test the full range of motion modifications with the two non-circular gear sets a total of 11 trials were conducted. The first trial served to set a baseline from which to compare the performance of the modified motion profiles. The baseline trials use a sets of conventional round gears $e=0$ for both the displacer and power piston and is equivalent to the piston motion of a conventional kinematic engine drive mechanism, but includes any system friction from having the gears present. Following establishment of the baseline both the power piston and displacer piston gear pairs were changed out in combinations. The final trial run was a further conventional baseline run to verify that engine performance had not drifted over the course of testing. The trial gearing configurations tested are detailed in Table 3, with trials numbered by their sequential chronological order.

Table 3. Trial Configurations.

\begin{tabular}{lccc}
\hline Trial Group & Trial No. & PP Gear & DP Gear \\
\hline Baseline & 1 & $e=0$ & $e=0$ \\
& 11 & $e=0$ & $e=0$ \\
Displacer Piston Dwell & 2 & $e=0$ & $e=1 / 5$ \\
& 10 & $e=0$ & $e=1 / 3$ \\
Power Piston Dwell & 6 & $e=1 / 5$ & $e=0$ \\
& 7 & $e=1 / 3$ & $e=0$ \\
Displacer and Power Piston Dwell & 5 & $e=1 / 5$ & $e=1 / 5$ \\
& 9 & $e=1 / 3$ & $e=1 / 3$ \\
Triangle Disp.* and Power Piston Dwell & 3 & $e=0$ & $e=1 / 5^{*}$ \\
& 4 & $e=1 / 5$ & $e=1 / 5^{*}$ \\
& 8 & $e=1 / 3$ & $e=1 / 5^{*}$ \\
\hline
\end{tabular}

*Displacer gears phased $90^{\circ}$ to crank arm to triangle profile motion 


\section{Results}

Results presented in this work focuses on the shaft power output of the engine under the trial configurations. Accordingly, the pressure volume indicator diagrams shown are for the maximum power output data point measured for each configuration. For all configurations this maximum power point occurred within \pm 1 loading increment of one another. Pressure results were taken directly from the collected data, while engine volume values were calibrated to the direct measurements of output shaft position in pre-trial calibrations. Discussion focuses on the achieved change in indicator diagram shape and gains made to that area.

Along with the indicator diagrams, plots of the shaft power as a function of engine running speed are provided for the full trial set. Power is calculated via the following relation:

$$
P W=\tau \cdot \omega_{\text {avg }}
$$

where

$$
\begin{aligned}
& P W=\text { Engine shaft power }[\mathrm{W}] \\
& \tau=\text { measured output shaft torque }[\mathrm{N} \cdot \mathrm{m}] \\
& \omega_{\text {avg }}=\text { Average output shaft angular velocity }
\end{aligned}
$$

The average angular shaft velocity was determined from measured counts of complete shaft rotations divided by the measured time to complete those rotations. The power curves presented only show data points of the unloading runs from stall point down to free running for clarity.

\subsection{Displacer Piston Dwelling}

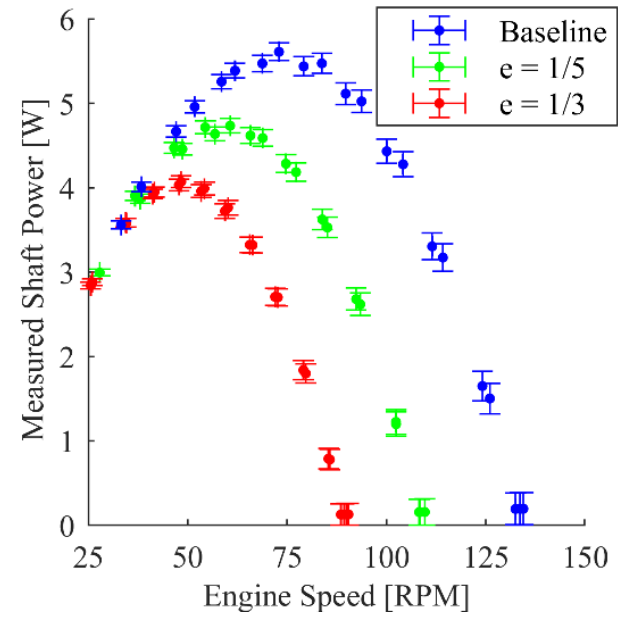

(a)

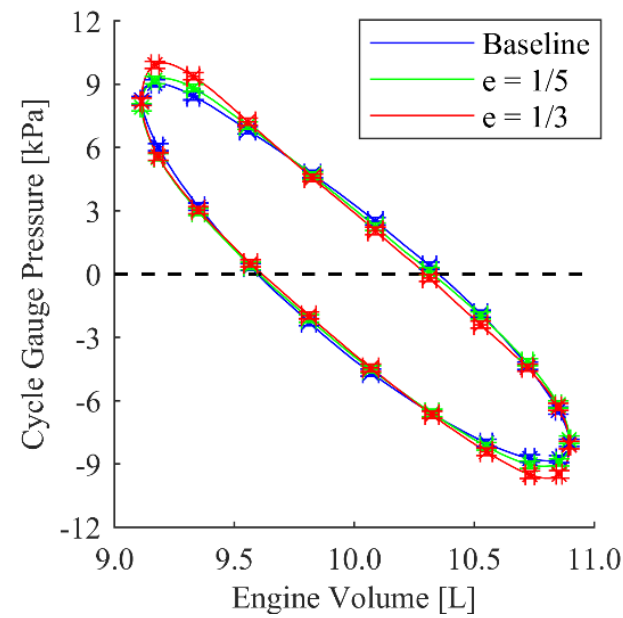

(b)

Figure 7. Displacer piston dwelling trials results showing the (a) P-V indicator diagrams for the maximum measured power sets and (b) the unloading power curves for all trials. 
Examining the power curve in Figure 7 (a) it can be seen that the dwelling of the displacer piston had a substantial impact on the power performance of the engine when compared to the baseline trial. The maximum power produced during the baseline trial was $5.61 \mathrm{~W}$ $\pm 0.10 \mathrm{~W}$, which reduced to $4.73 \mathrm{~W} \pm 0.09 \mathrm{~W}$ for the $e=1 / 5$ trail and further down to $4.07 \mathrm{~W}$ $\pm 0.07 \mathrm{~W}$ for the $e=1 / 3$ trial. Examining the data for the power curves, it is noted that for higher loadings, the reduction in shaft power is much lower than for light loadings that run at higher speed. This indicates that the reduction to power for the modified cycle is likely due to increased losses from flow friction in the engine cause by the much faster displacer piston motion caused by the non-circular gearing for equivalent output shaft speeds. Examining the shift of the power curves to the low speed end of the curve supports this conclusion.

When examining the P-V indicator diagrams shown in Figure 7 (b) it can be seen that the dwelled displacer piston motion profile does expand the indicator diagram, particularly at the corners. This is anticipated as the dwelled displacer motion would prolong the duration at which the gas remained in the expansion and compression space prior to the power piston undergoing the expansion and compression processes.

\subsection{Power Piston Dwelling}

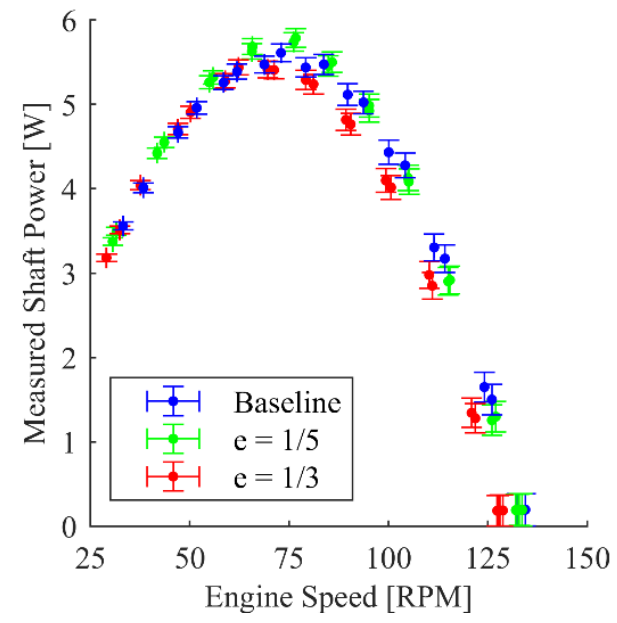

(a)

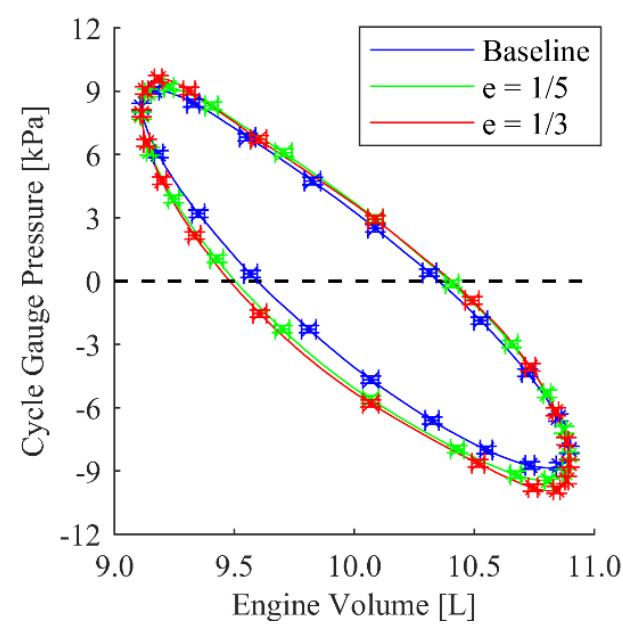

(b)

Figure 8. Power piston dwelling trials results showing the (a) P-V indicator diagrams for the maximum measured power sets and (b) the unloading power curves for all trials.

From the power curves shown in Figure 8 (a) it can be seen that the dwelling of the power piston has substantially less impact on the engine performance than the displacer piston dwelling. When compared to the baseline maximum power measurement of $5.61 \mathrm{~W} \pm 0.10 \mathrm{~W}$ the dwelled motion with the $e=1 / 5$ gear produced a maximum measured power of $5.79 \mathrm{~W}$ $\pm 0.11 \mathrm{~W}$, a modest increase. The trial of the $e=1 / 3$ gear produced a maximum measured power of $5.44 \mathrm{~W} \pm 0.09 \mathrm{~W}$, a modest decrease in power when compared to the baseline case. Apart from the small change in maximum power measured, the power curves of the dwelled and baseline are largely similar.

From Figure 8 (b) it can be seen that dwelling of the power pistons also had the effect of increasing the area of the P-V indicator diagram, but in a different way when compared to displacer piston dwelling. The area is has expanded from increased pressure swing in the expansion and compression portion of the cycle. This result makes sense given that dwelling 
the power piston results in shorter expansion and compression processes which would occur closer to the peak pressure swings from the displacer piston position.

\subsection{Combined Piston Dwelling}

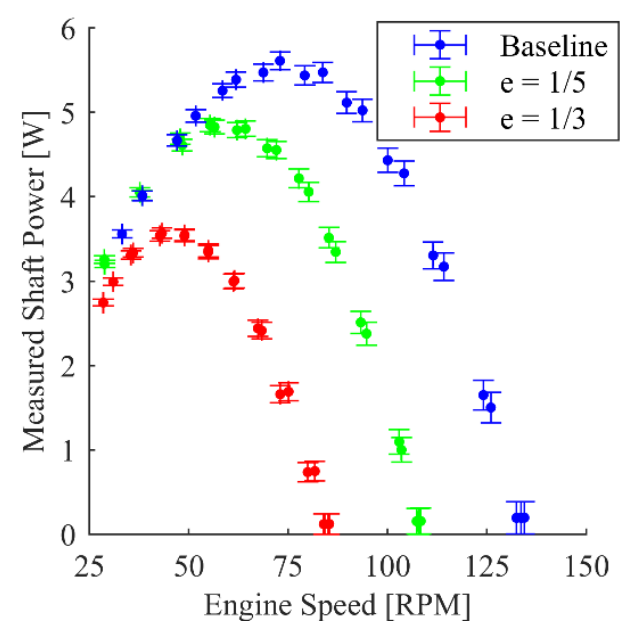

(a)

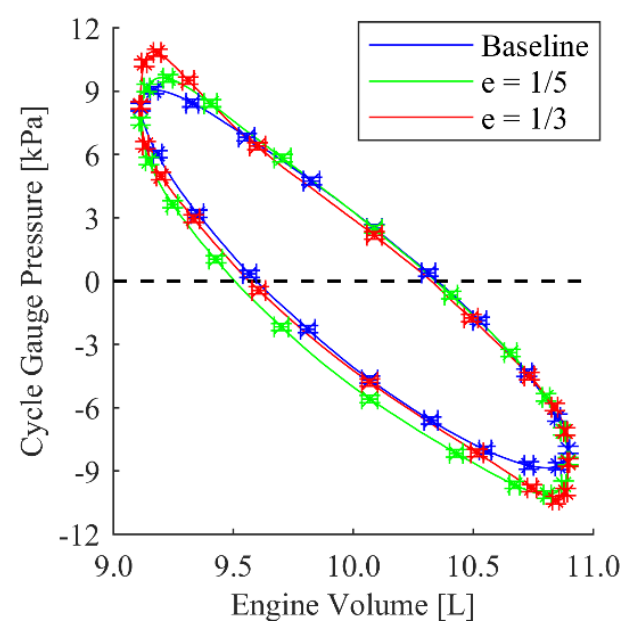

(b)

Figure 9. Combined displacer piston and power piston dwelling trials results showing the (a) P-V indicator diagrams for the maximum measured power sets and (b) the unloading power curves for all trials.

The combined displacer and power piston dwelling power curves are shown in Figure 9(a). The power curves are very similar to those shown in the dwelled displacer trials shown in Figure 7(a). The combined trials showed the most substantial decrease in maximum measured power, with the $e=1 / 5$ trial producing a maximum of $4.84 \mathrm{~W} \pm 0.08 \mathrm{~W}$ and the $e=1 / 3$ trial producing the lowest recorded maximum of any trial set a $3.57 \mathrm{~W} \pm 0.06 \mathrm{~W}$. These losses in power are likely dominated by the same power reducing effects of the displacer dwelling trials.

When examining the P-V indicator diagrams shown in Figure 9 (b) it is evident that the dwelling both the displacer and power piston had the anticipated effect of expanding the diagram closer to that of the ideal case. The curve from the $e=1 / 3$ in particular shows the strong pointed corners that are seen in the case of the ideal cycle.

\subsection{Power Piston Dwelling with Triangular Displacer Motion}

Results of the trials with the triangular displacer motion profile coupled with the dwelled power piston motion showed the most substantial performance improvements of all the tested configurations. From Figure 10 (a) it can be seen that the all triangle displacer motion profile trials had higher running speeds for light loading conditions. In the case where the displacer had triangular motion but the power piston was maintained near sinusoidal with $e=0$ gearing, there was a slight decrease in maximum power at a measured $5.50 \mathrm{~W} \pm 0.12 \mathrm{~W}$ when compared to the baseline maximum of $5.61 \mathrm{~W} \pm 0.10 \mathrm{~W}$. When the power piston was dwelled with the $e=1 / 5$ gear the maximum measured power increased to $5.84 \mathrm{~W} \pm 0.11 \mathrm{~W}$, the highest power output of all trials. For the $e=1 / 3$ trial the power also increased over the baseline to $5.7 \mathrm{~W} \pm 0.11 \mathrm{~W}$. 


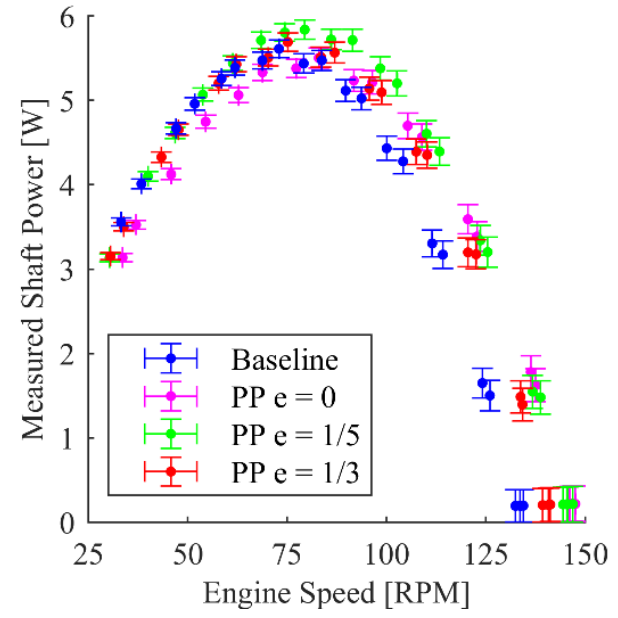

(a)

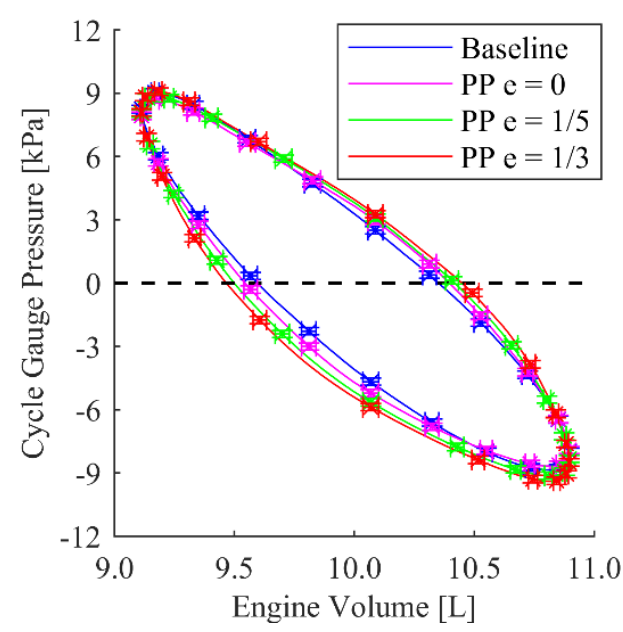

(b)

Figure 10. Trials results for the trials with triangular displacer motion profile and dwelled power piston motion showing the (a) PV diagrams for the maximum measured power sets and (b) the unloading power curves for all trials.

The changes to the P-V indicator diagrams shown in Figure 10 (b) caused by the triangular displacer motion profile and the dwelled power piston is very similar to the diagrams shown in Figure 8 (b). This is expected as the triangle displacer motion profile's shortening of the period of highest pressure at displacer top and bottom dead center is counteracted by the shorter expansion and compression processes of the dwelled power piston motion.

\section{Conclusions}

A low temperature difference gamma type Stirling engine was modified using non-circular oval elliptical gears to examine improving the thermodynamic performance and power output of the engine. Testing of the engine and drivetrain modifications revealed that the piston motion modification was able to achieve more discrete thermodynamic processes in the engine that approached the ideal Stirling cycle. However, any observed increases to P-V indicator diagram area had no substantial increases to the maximum power output of the engine. In the case of trials where the displacer piston was dwelled, the penalties to engine speed resulted in a decrease of maximum power. It is suspected that this resulted from the higher displacer piston velocities during the heat addition and heat rejection processes that were necessary to prolong the dwelling during the expansion and compression processes. In the worst case where both the displacer and power piston were dwelled with the $e=1 / 3$ gears the maximum power measured was reduced to $3.57 \mathrm{~W} \pm 0.06 \mathrm{~W}$ when compared to the conventional motion profile baseline maximum of $5.61 \mathrm{~W} \pm 0.10 \mathrm{~W}$.

Dwelling of the power piston was more successful, both expanding the indicator diagram and achieving slight increases in the maximum shaft power measurements of the engine. The most successful trial occurred when moving the displacer piston in a triangular motion profile while dwelling the power piston with the $e=1 / 5$ gear, slightly increasing the maximum power to $5.84 \mathrm{~W} \pm 0.11 \mathrm{~W}$ over the baseline case of $5.61 \mathrm{~W} \pm 0.10 \mathrm{~W}$.Overall the results indicate that deviating from the conventional, overlapping sinusoidal piston motion was possible, but it did not achieve substantial improvements to engine performance, and in the worst cases significantly decreased maximum power. 
The authors acknowledge financial support from the University of Alberta Future Energy Systems (FES) and Alberta Innovates (AI).

\section{References}

[1] B. Kongtragool and S. Wongwises, "A review of solar-powered Stirling engines and low temperature differential Stirling engines," Renew. Sustain. Energy Rev., vol. 7, no. 2, pp. 131-154, 2003.

[2] ÖkoFEN Heiztechnik GmbH, "Pellematic Condens," 2021. [Online]. Available: https://www.oekofen.com/de-de/pellematic-condens/. [Accessed: 30-Jun-2021].

[3] K. Wang, S. R. Sanders, S. Dubey, F. H. Choo, and F. Duan, "Stirling cycle engines for recovering low and moderate temperature heat: A review," Renew. Sustain. Energy Rev., vol. 62, pp. 89-108, 2016.

[4] J. Egas and D. M. Clucas, "Stirling Engine Configuration Selection," Energies, pp. $1-22,2018$.

[5] A. J. Organ, "An Ideal Thermodynamic Reference Cycle," in Thermodynamics and Gas Dynamics of the Stirling Cycle Machine, New York, USA: Cambridge University Press, 1992.

[6] I. Kolin, "Flat Plate \& Discontinous Motion," in Stirling Motor History - Theory Practice, Zagreb: Zagreb University Publication, LTD, 1991, pp. 213-226.

[7] I. Urieli and D. Berchowitz, "Introduction," in Stirling Cycle Engine Analysis, Bristol, England: Adam Hilger Ltd., 1984.

[8] J. R. Senft, "Energy Transfer In Cyclic Heat Engines," in Mechanical Efficiency of Heat Engines, New York, USA: Cambridge University Press, 2007.

[9] J. R. Senft, “Optimum Stirling engine geometry," Int. J. Energy Res., vol. 26, no. 12, pp. 1087-1101, 2002.

[10] N. Boutammachte and J. Knorr, "Field-Test of a Solar Low Delta-T Stirling Engine," Sol. Energy, vol. 86, no. 6, pp. 1849-1856, 2012.

[11] S. Kota, "Generic Models for Designing Dwell Mechanisms : A Novel Kinematic Design of Stirling Engines as an Example," vol. 113, no. March 1988, pp. 446-450, 2018.

[12] H. Fang, K. Herold, H. Holland, and E. H. Beach, "A Novel Stirling Engine With an Elliptic Drive," IECEC 96. Proc. 31st Intersoc. Energy Convers. Eng. Conf., vol. 2, pp. 1232-1237, 1996.

[13] F. L. Litvin, A. Fuentes-Aznar, I. Gonzalez-Perez, and K. Hayasaka, "Elliptical Gears and Gear Drives," in Noncircular Gears - Design and Generation, Cambridge University Press, 2009, pp. 40-70.

[14] C. Stumpf, "Parameter Optimization of a Low Temperature Difference Gamma-Type Stirling Engine to Maximize Shaft Power," University of Alberta, 2019.

[15] C. J. A. Stumpf, A. J. Hunt, and D. S. Nobes, "Effect of Scaling Up Low Temperature Differential Stirling Engines," in Proceedings of The 18th International Stirling Engine Conference, 2018, pp. 497-515. 